\title{
Analysis of Development Status of High Performance Water-based Drilling Fluid
}

\author{
Liquan Wang, Xin Zhang, Zicheng Zhang, Zhaoting Li, Wen Ren \\ Tianjin Branch, CNOOC (China) Limited, Tianjin 300452, China
}

\begin{abstract}
Deep wells, ultra deep wells and unconventional oil and gas exploitation have gradually become the focus of exploration and development. The oil-based drilling fluid is gradually replaced by water-based drilling fluid because of the impact of cost and environmental protection factors. In order to better replace oil-based drilling fluid, research on high-performance water-based drilling fluid has been carried out at home and abroad, and its comprehensive performance has gradually approached that of oil-based drilling fluid. The research progress and future development trend of high performance water-based drilling fluid abroad are introduced.
\end{abstract}

Keywords: Development status, Water-based drilling fluid.

\section{Introduction}

Drilling fluid is one of the important links of drilling engineering. The performance and cost of drilling fluid play an important role in exploration and development. In recent years, the exploitation of unconventional oil and gas resources such as deep wells, ultra deep wells, horizontal wells and shale gas has been increasing at home and abroad, and the drilling construction cost has been gradually reduced. Although the traditional oil-based drilling fluid is the best choice for drilling construction in terms of temperature resistance, lubricity and wellbore stability, its use is greatly limited by its high construction cost and impact on the environment. The traditional water-based drilling fluid can not meet the requirements of temperature resistance, lubricity and wellbore stability of special process wells. Therefore, the research and development of a high-performance water-based drilling fluid with relatively low cost, simple treatment and maintenance and similar performance to oil-based drilling fluid has become the focus of relevant scientific research institutions and large oil service companies at home and abroad. The research and development of high-performance water-based drilling fluid plays a vital role in reducing exploration and development costs, improving oil and gas field development benefits and promoting the large-scale development of complex oil and gas reservoirs [1-2].

At present, foreign large oil service companies such as M-I, Baker Hughes and Brad have developed corresponding high-performance water-based drilling fluid systems suitable for different construction environments. The concept of "drilling fluid customization" is introduced, and the corresponding drilling fluid formula is adopted according to the characteristics of different construction blocks. China started relatively late in the research and development of high-performance water-based drilling fluid, but after continuous efforts in recent years, the technical gap has been narrowed, and a series of high-performance drilling fluid systems suitable for domestic oilfields have been developed [3-4]. This paper mainly introduces the research progress of high-performance water-based drilling fluid abroad, and discusses the future development trend of high-performance drilling fluid.

\section{Research Progress of High Performance Water-based Drilling Fluid}

\subsection{Research Progress of Drilling Fluid System}

In recent years, major foreign oil service companies have conducted a series of comprehensive studies on high-performance water-based drilling fluid, in order to further reduce the cost, reduce the biological toxicity of drilling fluid and avoid the impact and damage of drilling fluid on the ecological environment while improving the temperature resistance, lubricity and inhibition of drilling system [5].

M-I SWACO is committed to optimizing the formulation of water-based drilling fluid to achieve the goal of oil-based imitation drilling fluid. M-I SWACO company took the lead in putting forward the concept of "drilling fluid customization" and developed ultradrill high-performance water-based drilling fluid system and Hydra Glyde high-performance water-based drilling fluid system according to the characteristics of different construction blocks [6]. Ultra-drill high performance water-based drilling fluid system is mainly composed of polyamide compounds as fluid loss reducer, polyanionic cellulose as tackifier and auxiliary inhibitor, polyamine compounds as main inhibitor, biopolymer as popular regulator, plant-based lubricating oil as lubricant and a speed increasing agent of patented technology, The temperature resistance of the formula can reach more than $130^{\circ} \mathrm{C}$. Hydra Glyde high performance water-based drilling fluid system mainly uses biopolymers as popular regulators, polyamine compounds as main inhibitors, and adds a patented film-forming agent to improve wellbore stability. While maintaining the characteristics of low cost and easy maintenance of water-based drilling, the above two systems have good environmental protection performance. In the process of field application, the above drilling fluid systems show the same drilling speed as oil-based drilling fluid, and reduce the downhole complexity, so as to provide a "fast, safe and flexible" drilling fluid technical solution for the drilling of complex structure wells. In addition, MI SWACO has also developed a new nano drilling fluid plugging agent, which inhibits fluid penetration and filtrate invasion by 
physically sealing micropores, so as to further improve the borehole stability of drilling fluid in shale formation. Moreover, this nano plugging agent also has good environmental protection characteristics and can be applied to environmentally sensitive areas [7-8].

Baker Hughes developed a high-performance drilling fluid system with the commercial name of Performax. The system is mainly characterized by the use of self-developed polyamine aluminum plugging agent (max-plex), nano plugging agent ( $\max$ shield), high-performance polyamine inhibitor ( $\max$ guard) and polymer film-forming agent (new-drill). The system has good micropore plugging ability, especially suitable for shale gas formation.

In addition, Performax high-performance drilling fluid system can resist temperature up to $150^{\circ} \mathrm{C}$, has good reservoir protection ability and environmental protection characteristics, and can meet the marine emission standards of the United States and the European Union [9].

Exxon has developed a high-performance water-based drilling fluid named EHT, which has good salt resistance and can be used for land and offshore drilling. The main treatment agents are cellulose tackifier and high temperature resistant polymer fluid loss reducer. The maximum bottom hole temperature for field application is $215^{\circ} \mathrm{C}$, and the maximum density is $1.86 \mathrm{~g} / \mathrm{cm}^{3}[10]$.

\subsection{Research Progress of High Performance Drilling Fluid Treatment Agents}

In order to achieve the construction performance of drilling fluid and meet the needs of field operation, a large number of treatment agents need to be used in the preparation of drilling fluid, and the use of treatment agents will inevitably bring pollution, especially in some areas with fragile ecological environment. In recent years, the environmental protection treatment agent and means of drilling fluid have been continuously developed, and the environmental protection treatment and recycling technology of waste rock cuttings of oil-based mud and waste drilling fluid has been further developed. However, the corresponding processing technology is complex, the equipment investment is large, and the processing cost is high. Therefore, foreign countries pay more attention to the research and development of environment-friendly drilling fluid treatment agents, so as to control the pollution of drilling fluid from the source and change from "terminal control" to "source control".

The research and development of low toxicity or non-toxic, biodegradable and environment-friendly drilling fluid treatment agent is a necessary link in the research and development of high-performance drilling fluid. In recent years, foreign oil service companies have successively developed new drilling fluid treatment agents, such as high temperature and salt resistant treatment agents and environmental protection lubricants. Among them, American Nalco company has developed AMPS / MBA / am copolymer. The copolymer still has good filtration reduction effect and flow pattern stability in high temperature and high salt environment. Polydrill developed by BASF company in Germany has been proved by indoor experiments that its temperature resistance can reach more than $220^{\circ} \mathrm{C}$, can be used in saturated brine, and has good resistance to calcium and magnesium ions.

In the aspect of deep processing, modification and optimization of degradable materials such as starch and cellulose, foreign companies have also developed supporting products one after another. Mi-swaco has developed a series of modified starch compounds poly Sal and floTrol, this kind of compound is resistant to temperature of $100^{\circ} \mathrm{C}-120^{\circ} \mathrm{C}$, biodegradable and has excellent environmental protection characteristics.

Baker Hughes company uses vegetable oil fatty acid and ethylene polyamine to synthesize an environmental friendly lubricant. The lubricant can be closely adsorbed on the surface of drilling tools and wellbore to form a very stable oil film, which can greatly increase the lubricity of drilling fluid and improve the stability of wellbore. Eco Global Solutions of the United States has developed an egstm-dfl environmental protection lubricant. Its excellent lubricity can greatly reduce the downhole torque and friction of the BHA, so as to improve the ROP.

\subsection{Relevant Environmental Protection Evaluation Standards for Drilling Fluid}

Although a lot of research on high-performance drilling fluid has been carried out at home and abroad, there is still a lot of work to be completed in establishing a unified environmental performance standard and evaluation method of drilling fluid. Drilling fluid related wastes are usually classified as industrial wastes, and the standards for the treatment of related wastes in different countries are also different, and the corresponding standards are more complex. In fact, the current laws and regulations on soil pollution and water resources pollution can not be fully applicable to the actual situation of drilling fluid and can not accurately reflect the environmental protection performance of drilling fluid, because even the original treatment agent is non-toxic and pollution-free, it can not prove that all materials will not produce biological toxicity after mixing. Therefore, the relevant environmental protection signs of drilling fluid still need to be further improved.

\section{Conclusions and Recommendations}

With the continuous development of drilling fluid technology, high-performance drilling fluid system which can partially replace oil-based drilling fluid has been developed at home and abroad, but the temperature resistance and wellbore stability still need to be further explored and improved.

Using natural products with low price and good environmental protection such as starch and cellulose as raw materials to further develop drilling fluid treatment agent is one of the main directions to reduce the cost of drilling fluid and improve the environmental protection characteristics of 
drilling fluid.

In the process of developing new high-performance water-based drilling, we should focus on improving the wellbore stability and reservoir protection ability of drilling fluid system, so as to provide a basis for high-performance drilling fluid to replace oil-based drilling.

The environmental protection evaluation standard of drilling fluid system should be further improved and a more professional evaluation basis should be established, so as to provide a more scientific basis for the application of drilling fluid.

\section{References}

[1] A. Bonnaccorsi, "On the Relationship between Firm Size and Export Intensity," Journal of International Business Studies, XXIII (4), pp. 605-635, 1992. (journal style)

[2] Wang Zhonghua. Progress in research and application of oil-based drilling fluids at home and abroad[J]. Fault Block Oil and Gas Field, 2011, 18(04): 533-537.

[3] Wang Zhonghua. The progress of drilling fluid technology at home and abroad and the relevant understanding of drilling fluid[J]. China and Foreign Energy, 2011, 16(01): 48-60.

[4] Yang Jin, Cao Shijing. The status quo and development trend of deepwater oil drilling technology[J]. Petroleum Drilling Technology, 2008(02): 10-13.

[5] Zhang Keqin, He Lun, An Shufang, Ding Tongwei, Song Fang. Introduction to foreign high-performance water-based drilling fluids[J]. Drilling Fluids and Completion Fluids, 2007(03): 68-73+94-95.

[6] Zhang Qigen, Chen Fu, Liu Yi, Xiong Ying. Development status of foreign high-performance water-based drilling fluid technology [J]. Drilling Fluids and Completion Fluids, 2007(03): 74-77+95.

[7] Wang Jianhua, Yan Jienian, Ding Tongwei. Research progress of high-performance water-based drilling fluids $[\mathrm{J}]$. Drilling Fluids and Completion Fluids, 2007(01):71-75+102.

[8] Zeng Yijin, Liu Jianli. The status and development trend of deep and ultra-deep well drilling technology[J]. Petroleum Drilling Technology, 2005(05): 4-8.

[9] Zhao Xionghu, Wang Fengchun. Research progress in the treatment of waste drilling fluids[J]. Drilling Fluids and Completion Fluids, 2004(02):45-50+66-67.

[10] Zhang Shaohuai, Zhang Jie. Development and innovation of China's drilling technology in the 21st century[J]. Acta Petrolei Sinica, 2001(06): 63-68+2-1. 